\title{
APPROACHES TO THE CHARACTERISATION OF TERTIARY AND SUPRAMOLECULAR PROTEIN STRUCTURES BY COMBINATION OF PROTEIN CHEMISTRY AND MASS SPECTROMETRY
}

\author{
M. PRZYBYLSKI ${ }^{1 *}$, V. SCHNAIBLE ${ }^{1}$, J. KAST ${ }^{1}$, S. BÜHLER ${ }^{1}$, J. MiChELS ${ }^{1}$,

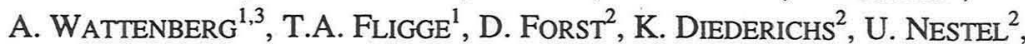 \\ K. ZETH ${ }^{2}$, M.O. GLOCKER ${ }^{1}$, AND W. WELTE ${ }^{2}$ \\ ${ }^{1}$ Faculty of Chemistry, and ${ }^{2}$ Faculty of Biology \\ University of Konstanz, P.O. Box 5560 M731, 78457 Konstanz, Germany \\ ${ }^{3}$ Present address: Institute of Physical Chemistry \\ University of Frankfurt, Frankfurt, Germany
}

\section{Abstract}

Soft-ionisation methods, particularly electrospray (ESI) and matrix-assisted laser desorption (MALDI) have enabled a breakthrough in the mass spectrometric structure analysis of proteins. Whereas ESI-MS provides direct information about solution structures and non-covalent interactions, the combination of mass spectrometry with structure-specific protein chemistry is emerging presently as a powerful tool for characterising tertiary structures and structure-function relations. Recent developments of chemical modification reactions are summarised which are suitable to the mass spectrometric analysis of reactive sites, surface topology and antigenic determinants in protein-tertiary structures, and can be efficiently employed in x-ray crystallographic structure determinations. Applications to the structure elucidation, and functional characterisation of porin-channel proteins and to leucine zipper protein-nucleotide complexes illustrate their efficiency in the analysis of two most important topics of structural biology, molecular recognition structures and biomacromolecular interaction.

\section{Introduction}

The development of efficient soft-ionisation methods of mass spectrometry (MS) has led to a recent breakthrough in the direct, molecular characterisation of biopolymers

* To whom correspondence should be addressed 
particularly polypeptides and proteins [1-3]. While fast atom bombardment (FAB-MS) and 252-Cf-plasma desorption (PD-MS) have enabled accurate molecular weight determinations of polypeptides and small proteins [3,4], biomacromolecules considerably beyond $100 \mathrm{kDa}$ have become feasible by electrospray-ionisation (ESI-MS) and matrix-assisted laser desorption (MALDI-MS) [5-7]. In addition to the determination of molecular weights, desorption-ionisation MS methods already have a number of established applications to primary structure analysis of proteins, such as full or partial sequence determination, characterisation of intracellular proteolytic processing pathways and the identification of covalent post-translational structure modifications [1,8-10]. A combination of MS with specific chemical (e.g. enzymatic) degradation, or collision-induced fragmentation/tandem-MS has been mainly used in these applications; direct mass spectrometric fragmentation has been successful also, particularly by ESI-MS [3,7].

Beyond the applications to primary structure analysis, recent approaches to the characterisation of higher-order (tertiary) structures, to structure-function studies and even specific non-covalent interactions of proteins are presently emerging as exciting new areas of mass spectrometry [3,5,11]; the recent discovery of ESI-MS as a tool for the direct analysis of supramolecular complexes and molecular recognition processes representing a major theme for this NATO conference [12,13]. Furthermore, the feasibility of soft-ionisation-MS methods to the analysis of multicomponent proteolytic mixtures (peptide mapping) has been demonstrated in several applications, and has been applied successfully to the molecular characterisation of chemical modification sites in proteins [14-17]. Since the initial studies employing the combination of specific protein-chemical modification reactions and mass spectrometric peptide mapping $[3,14]$, useful structural information has been obtained already, e.g. on surface topology, tertiary structure micro-environment and specific antigenic binding sites (epitopes) to antibodies [16-24]. Such applications have been further enhanced by the recent analytical development of ESI-MS showing that (i) specific biopolymer interactions can be characterised at near-physiological conditions in solution; and (ii) information about solution structures and conformation of proteins can be derived from multiply-charged ions in ESI spectra. [5,11].

In this article, analytical concept and hitherto successful protein-chemical modification reactions in the characterisation of protein tertiary structures and supramolecular association are summarised in a first paragraph. Model studies with proteins of known crystal structures show that a number of tertiary structure-selective modification reactions are available at present and further specific reaction types for single amino acids are likely to be developed in the near future. Recent applications to porin channel proteins are discussed in a second paragraph which demonstrate the efficiency of protein-chemical modification and mass spectrometry, in combination with $\mathrm{x}$-ray crystallography for the structure determination of an important class of membrane proteins [25]. As described in several recent publications [5], the feasibility of ESI-MS for probing non-covalent biomacromolecular interactions has been well illustrated in studies on the structure elucidation of leucine-zipper polypeptide complexes with polynucleotides, encompassing two different types of hydrophobic and ionic interactions [26,27]. Recent studies with several leucine-zipper polypeptides as model structures for transcription activators are summarised in this article, demonstrating ESI-MS in combination with protein chemistry as a powerful methodology, and alternative to the classical electrophoretic analysis of proteinnucleotide interactions.

\section{Characterisation of Tertiary and Supramolecular Protein Structures by Selective Chemical Modification and Mass Spectrometry}

\subsection{ANALYTICAL CONCEPT AND METHODOLOGY FOR THE CHARACTERISATION OF SITE-SPECIFIC MODIFICATION REACTIONS}

Chemical modification reactions have long been employed in structure-function studies of proteins, e.g. for modifying enzymatic properties and immunological reactivity $[28,29]$, and differential chemical modification has been used previously for probing specific protein-protein interactions such as in antigen-antibody complexes [30]. Although a number of reaction types for amino acid residues have been evaluated already until ca. 1980 (s. [28] for a review), their full development has been impeded by the lack of specific methods for characterising the multiple reaction products in proteins [3]. Conventional analytical methods generally require laborious procedures (such as radioactive labelling [29]); they do not enable a molecular homogeneity assessment of protein derivatives, and do not provide unambiguous identification of modification sites. Site-specific mutations in structure-function studies of proteins have become increasingly amenable in the last years through recombinant bacterial expression variants [31], yet this approach is restricted to proteinogenic amino acids. Thus, a number of recent studies have shown that there is a considerable need for complementary approaches that can provide information on chemical properties and reactivities in protein structures, in spite of the rapid development of $\mathrm{x}$-ray crystallography and multidimensional NMR methods in the last years [32-36] (s. also cartoon in the preface of this volume).

In contrast to conventional methods based on electrophoretic or chromatographic procedures, mass spectrometric peptide mapping of proteolytic digest mixtures has been found highly suitable for the rapid and sensitive identification of multiple chemical modification sites in proteins $[16,17]$. Following initial studies showing the feasibility for the mass spectrometric analysis of limited, tertiary structure-selective chemical modifications [16,37], a general analytical scheme has been developed for the molecular characterisation of "native-like" chemically modified proteins and protein 
complexes, as shown schematically in Figure 1 [3]. In the first step of this procedure, the precise extent of modification in a protein, i.e. the number and distribution of partially modified residues are identified by direct mass spectrometric molecular weight determination. Both MALDI-MS and ESI-MS have been found suitable for this purpose, depending on the mass and/or component resolution required for the type of modification [3]. However, an additional dimension of information is provided by ESI-MS by the distribution of multiply charged ions of protein derivatives which have been termed "charge structures" [5] due to their correlation with (e.g. native or denatured) conformation states in solution $[5,11,16]$. This feature of ESI-MS provides a relative comparison of conformational states and hence a molecular assessment of the structural selectivity for a protein-chemical modification which has not been feasible hitherto by conventional methods. Thus, identical or very similar charge structures of ions for partially modified proteins indicate a native-like structure for modification reactions that do not cause charge alterations (vd. infra; Figure 2) [3]. Corresponding data from ESI mass spectra have been particularly useful for the crystallisation of selectively modified proteins [38], and in the functional characterisation of protein complexes, as shown below for ion-channel proteins.

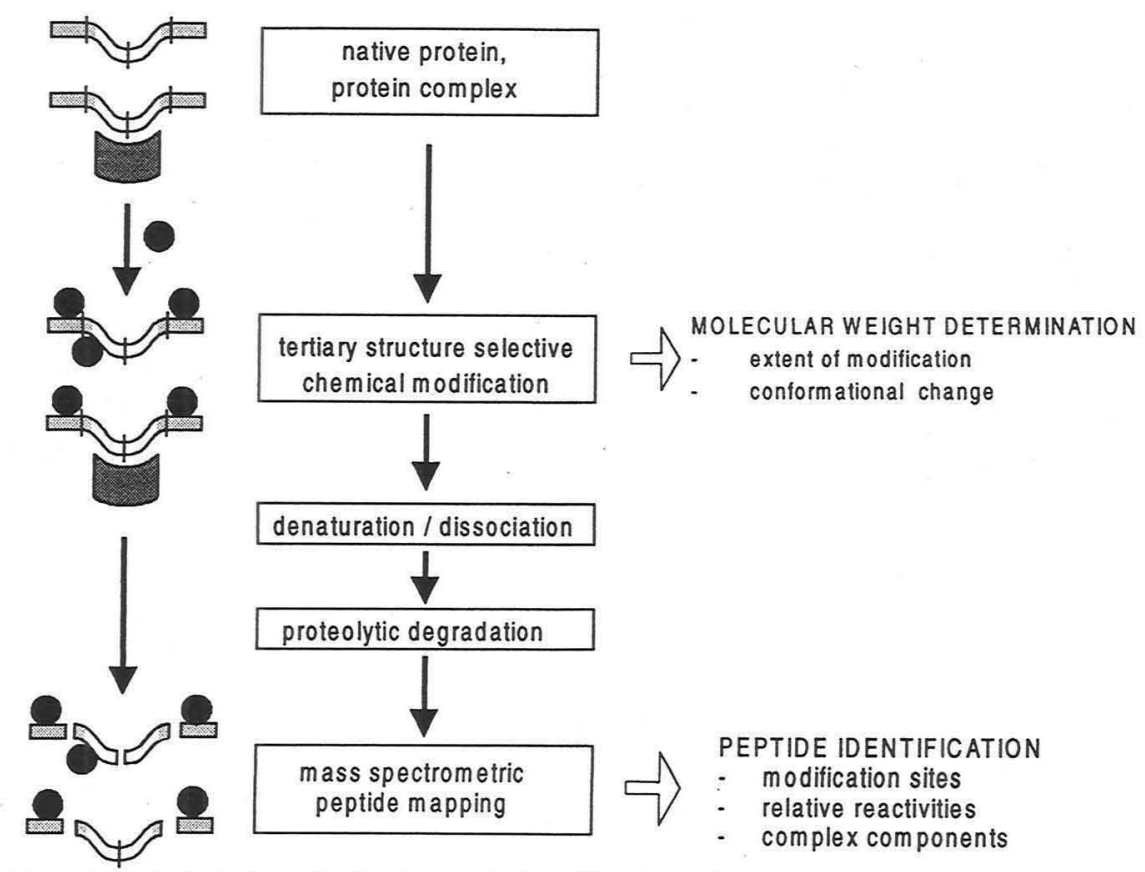

Figure 1. Analytical scheme for the characterisation of functional sites in protein tertiary structures and supramolecular complexes by selective chemical modification and mass spectrometric peptide mapping. Modification groups and proteolytic cleavage sites are indicated by filled circles and lines, respectively. The white area represents a shielded sequence in a protein complex, as adopted from the general mass spectrometric epitope mapping procedure for protein antigens in ref. [18]
Following the direct characterisation of protein derivatives, denaturation (complex dissociation) and proteolytic digestion is performed, and the sites of modifications are identified by mass spectrometric peptide mapping of peptide fragment mixtures [16]. Moreover, assignments of relative reactivities at specific amino acids can be derived from series of partially modified proteins or protein complexes. Such direct determinations of reactive sites in intact protein structures can be assessed by comparison of chemical modifications in proteins with model peptides, under identical reaction conditions, and have been found highly useful in structure-function studies $[5,17,39]$.

Examples of modification reactions at specific amino acid residues evaluated by mass spectrometric peptide mapping, and hitherto successful applications in protein structural studies are given in Table 1. The extent of modifications (conversion curves) can vary from essentially quantitative modification of lysine-e-amino groups in globular proteins according to their relative surface accessibilities [16], to high structural selectivity as has been observed in the modification of Arg residues by 1,2-diketone-derivatives [17,40]. Thus, amino acylations of Lys residues in aqueous solution ( $\mathrm{pH} 6.5)$, e.g. by acetyl or succinyl groups have provided astounding, detailed structural information [3]; acylation sites are readily identified by peptide mapping using serine proteases, confining cleavage sites to Arg residues. Reactivities at lysine-

TABLE 1: Examples of modification reactions of specific amino acid residues employed in the mass spectrometric characterisation of protein tertiary structures and protein interactions.

\begin{tabular}{|c|c|c|c|c|}
\hline amino acid & reagent & product & application & refs \\
\hline $\begin{array}{l}\text { lysine, } \\
\text { N-Terminus }\end{array}$ & $\begin{array}{l}\text { carbonic acid a } \\
\text { anhydride }\end{array}$ & acyl-Lys & $\begin{array}{l}\text { surface topology, } \\
\text { reactive sites, } \\
\text { epitope mapping } \\
\text { binding surfaces }\end{array}$ & {$[3,16,45]$} \\
\hline arginine & 1,2-diketone & $\begin{array}{l}\text { N7,N8-(1,2-dihydroxyethylene)- } \\
\text { Arg }\end{array}$ & $\begin{array}{l}\text { microenvironment } \\
\text { structures }\end{array}$ & {$[17,22]$} \\
\hline \multirow[t]{2}{*}{ tyrosine } & iodine & 3-iodo- and 3,5-diiodo-Tyr & $\begin{array}{l}\text { heavy atom } \\
\text { insertion/x-ray } \\
\text { crystallography } \\
\text { surface topology }\end{array}$ & {$[36,37]$} \\
\hline & $\begin{array}{l}\text { tetranitro- } \\
\text { methane }\end{array}$ & 3-nitro-Tyr & surface topology & [37] \\
\hline \multirow[t]{2}{*}{ cysteine(s) } & iodoacetamide & s-carbamido-methylene-Cys & $\begin{array}{l}\text { redox catalysis; } \\
\text { protein folding }\end{array}$ & {$[10,39]$} \\
\hline & $\begin{array}{l}\text { arsonous acid } \\
\text { derivatives }\end{array}$ & arsonous acid dithioester-Cys & & [23] \\
\hline histidine & $\begin{array}{l}\text { diethylpyro- } \\
\text { carbonate }\end{array}$ & carbethoxy-His & reactive centres & [22] \\
\hline
\end{tabular}


amino groups were found to correlate well with relative surface accessibilities (e.g. at a $1.4 \AA$ van der Waals sphere of solvent accessibility [41]) for several proteins with known structures, whereas $\mathrm{pK}_{\mathrm{a}}$-differences were only found significant for the rapid $\mathrm{N}$-terminal acylation $[17,42]$. This feature has provided useful molecular information on surface topology and accessible reactive sites, as illustrated in structure-function studies of porin ion-channel proteins (see also ref [43], this volume). In hen egg-white lysozym (HEL), the most reactive Lys-97 residue has the highest surface accessibility [17]. The selectivity of the acylation has been established by crystal structure determination of its Lys-97-monosuccinyl derivative (s. 2.2; Figures 4,5). A new application is the recently explored fixation of heavy-atom derivatives in proteins by amino-acylation (s. 2.2).

Furthermore, Lys-amino-acylation has been successfully employed in the characterisation of protein interactions, such as antigenic determinant structures (epitopes) to monoclonal antibodies and binding surfaces in complexes of the elongation factor EF-Tu/Ts proteins [44]. Approaches to the identification of epitope structures, including conformationally assembled epitopes, by differential chemical modification and mass spectrometric peptide mapping of antigen-antibody complexes (epitope-excision), and applications to Troponin-T and HEL epitopes have been described in recent publications $[20,21,45]$.

In contrast to the amino-acylation, high structure-dependent selectivity has been found for the bifunctional modification of cysteine-thiol groups by arsonous acid derivatives (phenyl-arsinoxides [23]) which have been employed in cysteine folding pathways $[3,10]$ and for the Arg-specific modification by 1,2-cyclohexanedione (CHD) [17]. The latter reaction is an example for the efficiency of mass spectrometric peptide mapping in probing microenvironment structures. Reactivity of $\mathrm{Arg}$ residues with 1,2-diketones and formation of dihydroethylene adducts is only found for suitable intramolecular proton acceptor residues and sufficient accessibility of the guanidinonitrogen atoms, as illustrated by the reaction pathway in Figure 2. Partial structures around two reactive Arg residues (Arg-10, -33) in bovine RNAse A and HEL are shown in Figure 2. In HEL, selective modification was found for Arg-5, -12, -112, and -73 which all have suitable intramolecular hydrogen acceptor groups [17]. The only modification site in RNAse A was identified at the Arg-39 residue having suitable asymmetric accessibility for the guanidino group; the lack of reactivity at other Arg residues is explained either by effective shielding of both guanidino-nitrogen atoms (Arg-10) or the lack of deprotonating residues in the microenvironment (Figure 2) [46].

The present applications and recent studies utilising new types of proteinchemical reactions indicate broad analytical potential for structure-reactivity correlations by selective chemical modification and mass spectrometry. Although still in the stage of analytical development, the further evaluation of this protein-chemical approach as a complement to site-specific mutation using recombinant biotechnology will be interesting in the future.
HEL

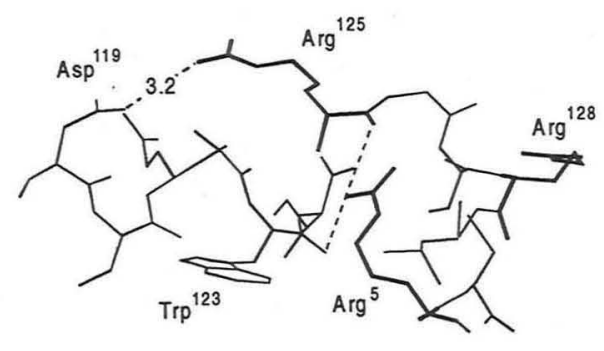

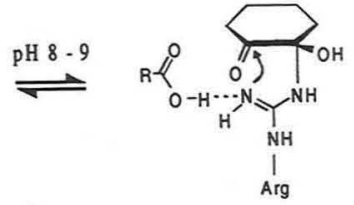

Arg
RNAse A

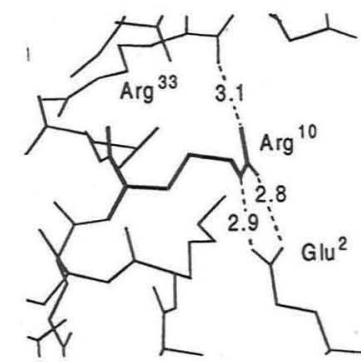

$\underset{ }{\rightleftharpoons}$

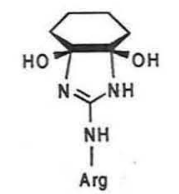

Arg

Figure 2. Tertiary structures around Arg-5 and Arg-125 residues in HEL and Arg-10, Arg-33 residues in Figure 2. Tertiay RNAse A, and reaction scheme of lhe Aress of CHD in sodium borate buffer ( $\mathrm{pH} 8.5$ ), under identical incubated for 2 his conditions. Modification sites were determined by ridues have suitable hydrogen-bond distances to the mapping. The reactive Arg-125 and Arg-s resid, respectively [17]. The two nitrogen atoms of Arg-10 Asp-119-carboxylate and the Trp-123 peptide bond, respectively [17]. The two nitrogen atoms of Arg-10 in RNAse $\mathrm{A}$ are at hydrogen-bond distance to Glu-2-carbonyl $(3.3 \AA$ ) no acceptor group is found in the environment of Arg-33. Structural data in the upper panel are (3.3 A), no acceptor group is found in the environment of Arg-33.

\subsection{PROTEIN-CHEMICAL MODIFICATION REACTIONS IN STRUCTURE DETERMINATION BY X-RAY CRYSTALLOGRAPHY}

Specific covalent modification reactions have not yet been considered in detail and experimentally explored in X-ray crystallographic structure determination procedures of proteins. The lack of work in this area is in marked contrast to the successful use of recombinant protein mutations for crystallisation and structure elucidation $[33,36]$. Only few previous studies have been performed using chemically modified proteins in crystallisation trials; however, an illustrative example is the recent crystallisation of a chlorophyll membrane protein which was successful only upon a specific $\mathrm{N}$-alkylation reaction [38]. Major obstacles, considered in the past to prevent the use of chemical modification have been (i), problems in the preparation/purification of protein derivatives with suitable homogeneity; and (ii), insufficient characterisation methods. As pointed out in the preceeding paragraph, mass spectrometry enables the molecular 
characterisation of chemically modified proteins and, hence, provides the basis for evaluating the homogeneity of proteins suitable for $\mathrm{X}$-ray crystallography.

The well-known structure of HEL was utilised as a model system to study the effect of amino-acylation on the crystallisation and structure determination. A series of succinylated HEL derivatives were prepared by reaction with succinic-anhydride as previously described [16], and protein derivatives with different extent of modification (1-4 succinyl groups) purified by gel filtration and HPLC (Figure 3). Two succinylated proteins were characterised by MALDI-MS and ESI-MS having average contents of one and two succinyl groups, and yielded isomorphous crystals with the native protein (Figure 4). The succinylation site was identified at Lys-97 by mass spectrometric peptide mapping using Lys-C-protease, consistent with the previously described highest surface accessibility for this most reactive lysine residue [3].

The structure determination of the monosuccinylated-HEL, was performed by multiple isomorphous replacement with the crystals shown in Figure 4 diffracting to $2.6 \AA$, and provided unit cell constants and difference Fourier electron density maps nearly identical with that of the native protein [47]. In the structure (Figure 5) the

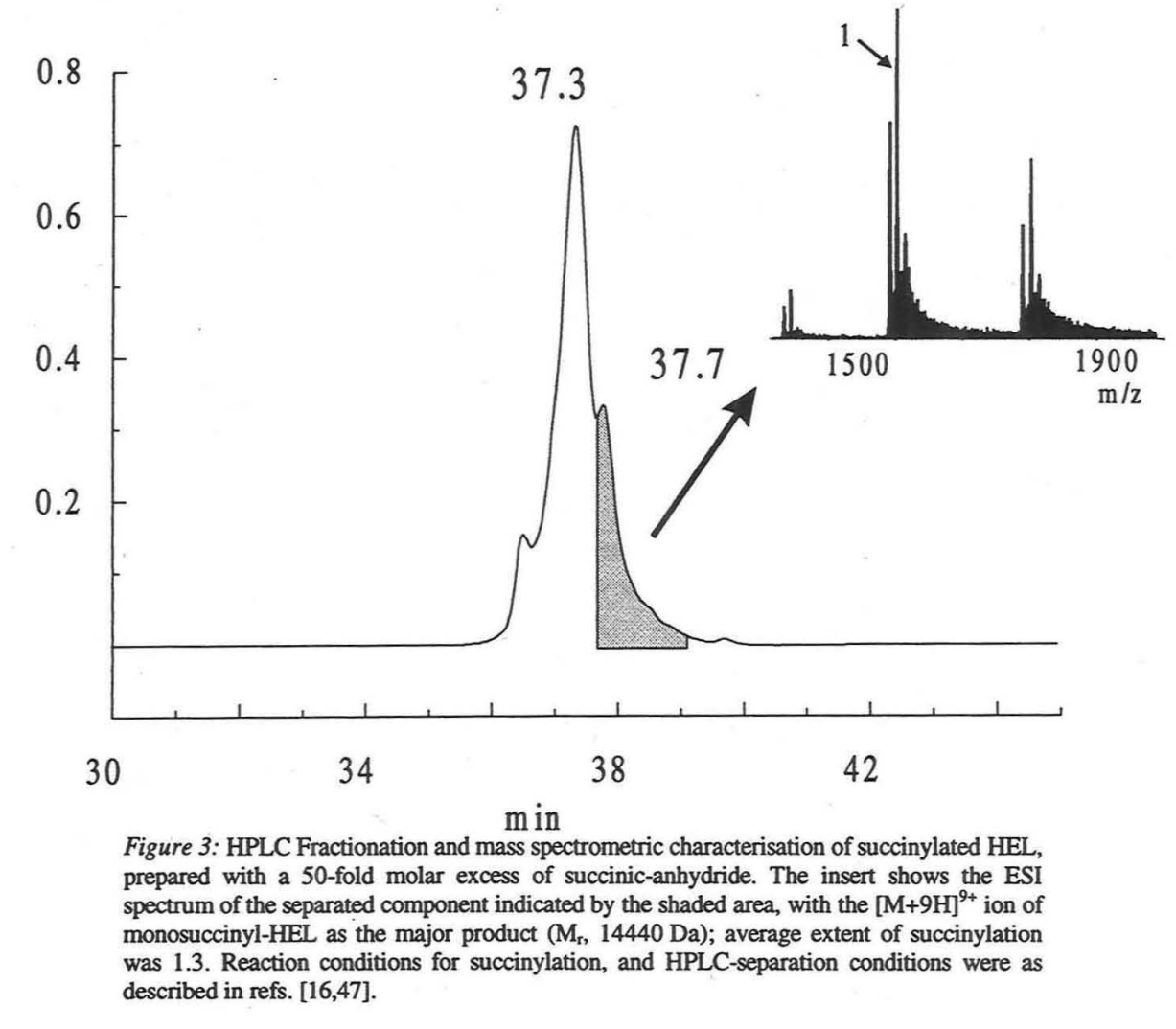

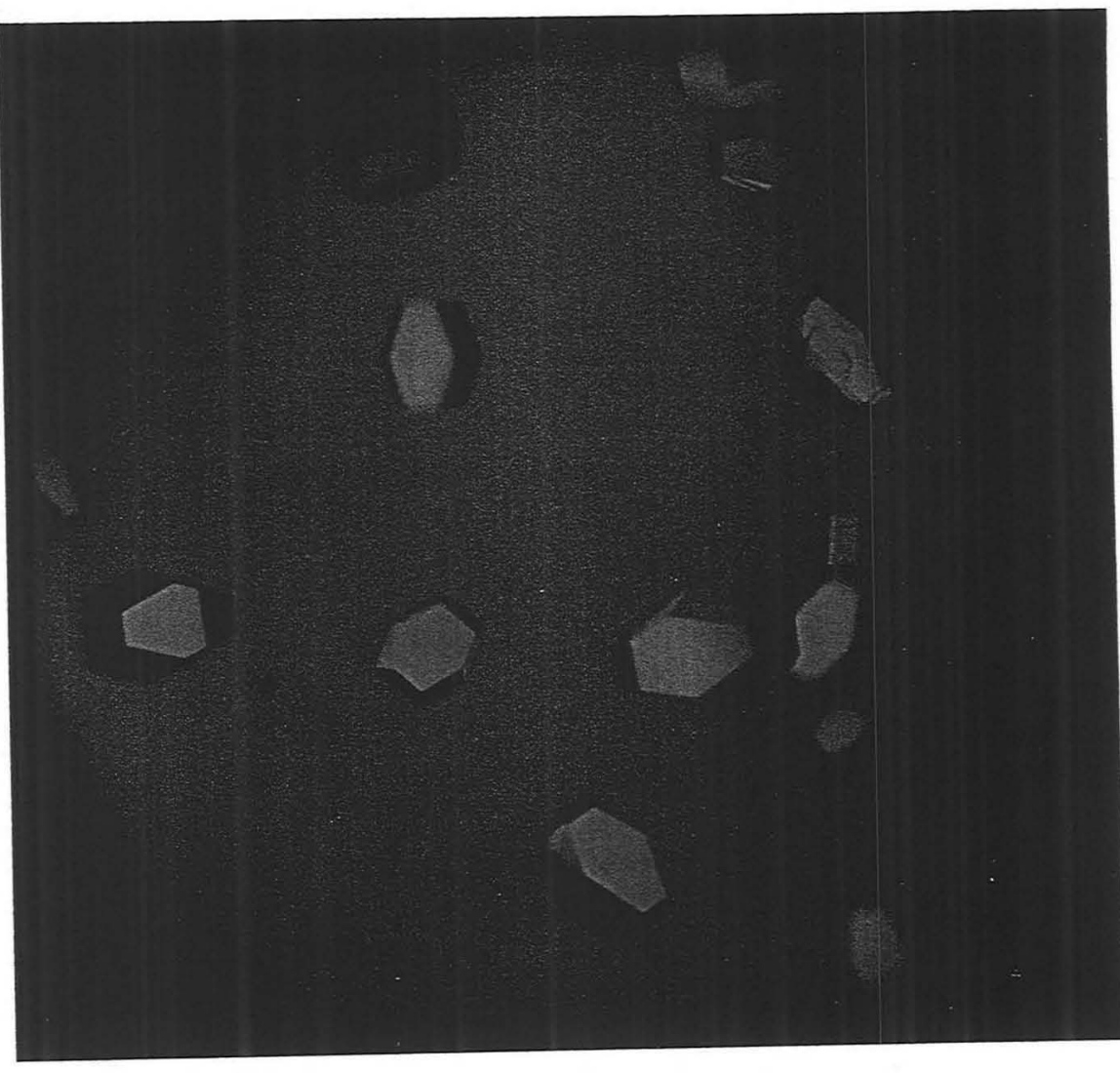

Figure 4. Photograph of hexagonal single crystals of succinylated HEL isolated by HPLC (s. Fig. 3).

electron density at Lys-97 was not sufficient to ascertain the location of the succinyl group, so that this group was added arbitrarily. The failure to identify the modified residue may be explained by a high flexibility of the succinyl group at the surfaceexposed Lys-97 residue. This result is consistent with recent $\mathrm{x}$-ray crystallographic exposed Lys-97 residue. Thified porins in which modification sites were not detected from electron density maps, despite the preparation of suitably diffracting crystals (see below, 3.1).

Several effects may be responsible for the failure in crystal structure analysis to identify partial structures such as modification groups of high mobility which are difficult to predict with the present methodology of difference electron density maps $[25,48]$. Hence, the capability of MALDI-MS and ESI-MS to directly assess complete chemical structures and post-translational modifications in proteins, renders x-ray 


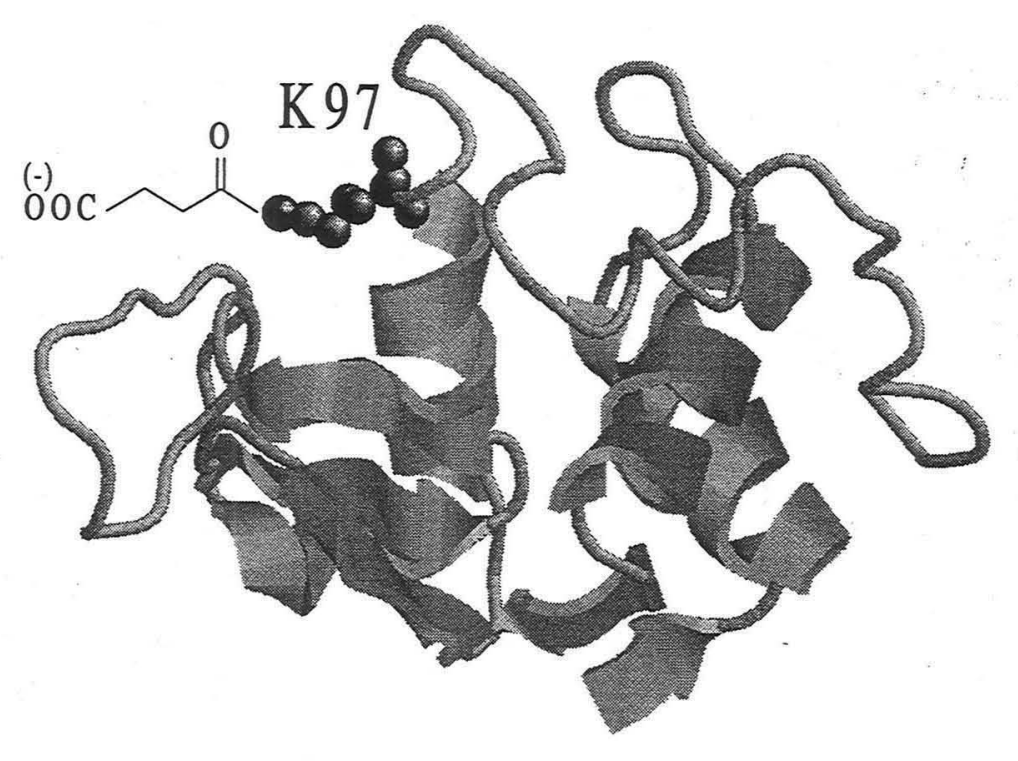

Figure 5. Structure model of lysine-97-succinylated HEL determined by x-ray crystallography (s. Fig. 3). The succinyl-group at K-97 was not determined from the electron density map.

crystallography and mass spectrometry particularly effective as complementary methods. An important application area may be the further development and refinement of isomorphous replacement methods by heavy-atom derivatives for phase assignment in crystal structure analysis. This methodology is largely based at present on trial- and error-procedures (e.g. soaking or co-crystallisation [36]). A new concept pursued in our laboratory is the development of defined procedures for the covalent fixation of heavy-atom derivatives at conditions that still maintain intact protein structures, e.g. by the amino-acylation described above.

First model studies have been performed with iodinated derivatives of lysozyme (cf. Table 1), and with HEL amino-acylated by [(succinimidooxy)carbonyl]methylmercuri chloride. The ESI mass spectrometric characterisation of the corresponding chloromercuri-acetyl-HEL provides the possibility of selecting suitable derivatives with exactly defined chemical structure, such as for the Lys-97-monosubstituted HEL derivatives (Figure 6). The direct characterisation of molecular stoichiometries for heavy-atom protein derivatives may lead to improved crystallisation methods, as well as procedures for the assignment of electron density maps.
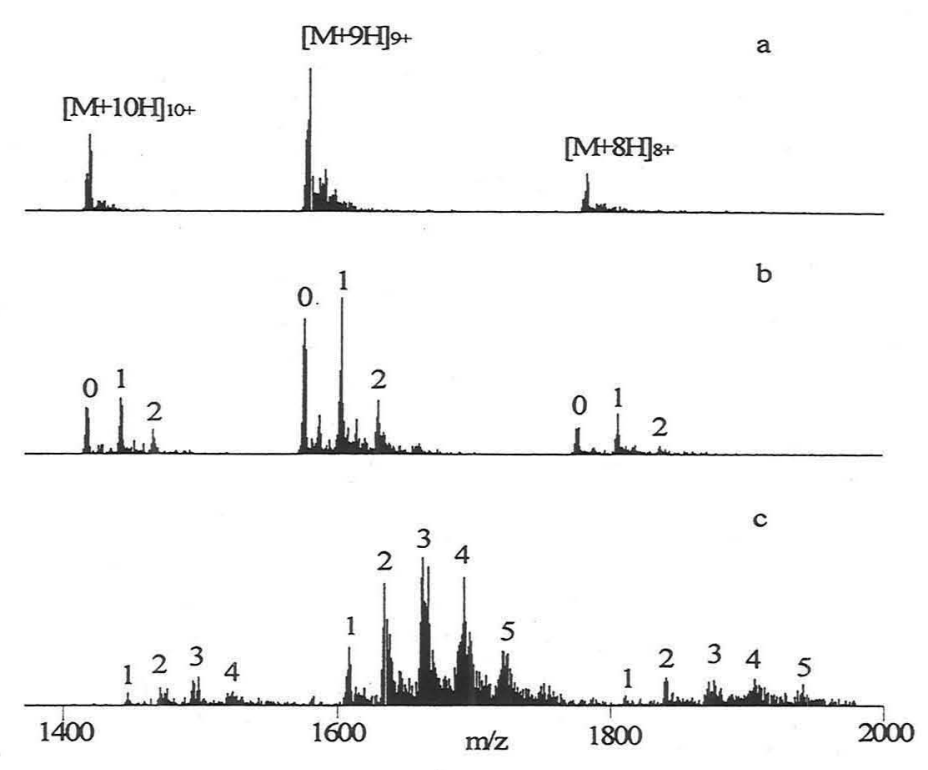

Figure 6. ESI-mass spectra of (a) native HEL; (b,c), chloromercuri-acetyl-HEL derivatives modified with a two-fold and five-fold molar excess of [(succinimidooxy)carbonyl]methyl-mercuri chloride, respectively. The numbers denote the number of chloromercuri-acetyl groups introduced.

3. Mass spectrometric and X-Ray Crystallographic Structure Determination of Porin-Channel Proteins

\subsection{STRUCTURE DETERMINATION AND ION TRANSPORT PROPERTIES OF SUCCINYLATED PORIN FROM RHODOBACTER CAPSULATUS}

The permeability barrier of gram-negative bacteria is overcome by water-filled channeltype porins which form the major protein component in the outer membrane and allows the permeation of ions and other small molecules up to a molecular weight of ca. $800 \mathrm{Da}[25,49]$. To date, the structures of only five bacterial porins have been completely determined by X-ray crystallography, such as the ion-channel porin from Rhodobacter capsulatus (R.c.-porin) [25]. Generally, they form trimeric complexes consisting of 16-18-stranded $\beta$-barrels of high stability, which have a similar periplasmic pore mouth but different loops in the medium-opposed mouths (s. Figures 7 and 8, and ref. [43], this volume). The structures, transport functions and 
selectivities, and membrane association of general diffusion channels as well as specific porins have been subject of detailed studies by several groups in the last years, both in the soluble and the solid (crystalline) state [25,43,50]. Methods for the direct mass spectrometric characterisation of porins in solubilised, detergent-containing preparations have been recently developed [51-53].

A characteristic structure element of R.c.-porin is a central constriction loop inside the $\beta$-barrel cylinder which constricts the free cross section to approximately $8 \times 10 \AA$ and shows a highly asymmetric charge distribution of acidic and basic amino acids, opposite to each other [51]. Ion conductance studies with lipid membranes in vitro have strongly suggested this peptide loop as the central site determining cation/anion permeability and transport selectivity [43]. The functional role of charges near the pore mouth of R.c.-porin and other ion channels has been intensively discussed in theoretical work. In order to introduce new negative charges, the R.c.-porin was succinylated with succinic anhydride at $\mathrm{pH} 6.5$, using conditions that where established previously to provide selective, native-like acylation of amino groups [16]. The structure of the major, purified succinylated porin derivative was identified by X-ray crystallography and mass spectrometry. An isomorphous crystallisation with space group and unit cell constants very similar to the native porin was found which enabled the structure elucidation at $2.4 \AA$ resolution (s. Figure 7 and ref. [51]). However, the electron density maps did not permit an assignment of the succinylated groups except for Lys-46, one of the lysine residues at the constriction site of the inner channel surface. Ion transport experiments in black lipid membranes revealed substantial channel forming activity of the succinylated protein with a higher single channel conductance than the native porin, and a significant increase of the cation selectivity (Table 2).

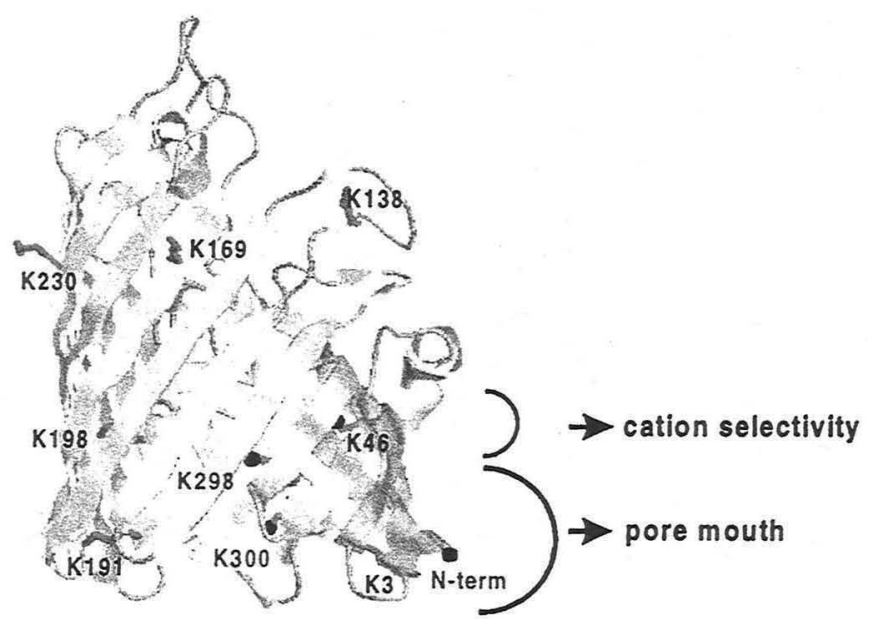

Figure 7. Point-charge structure model of tetrasuccinylated porin from Rhodobacter capsulatus [51].
The precise extent and the sites of succinylations were determined by MALDI-MS which revealed the presence of a mono- (MS-porin) and exactly tetra-succinylated protein (TS-porin), for the porin derivative with isomorphous crystal structure $\left(\mathrm{M}_{\mathrm{w}}\right.$, $31541 \mathrm{Da}$. for the native R.c.-porin; $31941 \mathrm{Da}$ for TS-porin) [51]. The complete identification of the succinylation sites in TS-porin was obtained byMALDI-MS peptide mapping of proteolytic peptides, and by mass spectrometric and sequence analysis of HPLC-isolated peptide fragments. These results revealed the selective modification of three Lys-amino groups (K-46, K-298, K-300) and the N-terminus. All succinylation sites were found at the inner channel surface. Lys-46 is located at the channel constriction site, while the other succinylated residues are all near the periplasmic pore mouth. As shown by the structure model of TS-porin (Figure 7), this specific pattern is well compatible with a point charge model [50] that directly provides evidence to explain the concomitant increase of both the single-channel conductance and the cation selectivity.

TABLE 2: Modification sites of succinylated porins and ion transport properties through black-lipid membranes.

\begin{tabular}{|c|c|c|c|c|c|}
\hline \multirow[t]{2}{*}{ Protein } & \multirow{2}{*}{$\begin{array}{l}\text { succinylation sites/ } \\
\text { proteolytic peptides }^{\mathrm{a}}\end{array}$} & \multicolumn{2}{|c|}{$\begin{array}{l}\text { single-channel } \\
\text { conductance }^{\mathrm{b}}\end{array}$} & \multicolumn{2}{|c|}{$\frac{\text { membrane }}{\text { potential }^{\mathrm{c}}}$} \\
\hline & & $\mathrm{c} / \mathrm{KCl}$ & $\mathrm{G}(\mathrm{nS})$ & $\mathrm{Vm}(\mathrm{mV})$ & $\mathrm{P}$ \\
\hline \multirow[t]{3}{*}{ n-porin ${ }^{d}$} & $934(1-9)$ & 0.10 & 0.32 & 39 & 9.0 \\
\hline & $4345(27-69)$ & 0.03 & 0.09 & & \\
\hline & $6824(231-298)$ & 0.01 & 0.03 & & \\
\hline \multirow[t]{3}{*}{ MS-porin } & $\alpha-\mathrm{NH}_{2} / 1035(1-9)^{*}$ & 0.10 & 0.5 & 44 & 13 \\
\hline & $\mathrm{K}-46 / 2199(42-62) *$ & 0.03 & 0.24 & & \\
\hline & & 0.01 & 0.09 & & \\
\hline \multirow[t]{3}{*}{ TS-porin } & $\alpha-\mathrm{NH}_{2} / 1035(1-9)^{*}$ & 0.10 & 0.90 & 49 & 23 \\
\hline & $\mathrm{K}-46 / 2199(42-62) *$ & 0.03 & 0.53 & & \\
\hline & $\mathrm{K}-298, \mathrm{~K}-300 / 3390(270-301)^{* *}$ & 0.01 & 0.30 & & \\
\hline
\end{tabular}

${ }^{2}$ Molecular weights and sequences determined by MALDI of tryptic peptides and Edman sequence analysis [51]. ${ }^{b}$ Average single channel conductance $(\mathrm{G})$ in diphytanoyl-phosphatidylcholine/n-decane membranes [50]. c, molar

'Vm, zero-current membrane potential (s. ref. [25]); $P$, permeability ratio $P_{\text {cation }} / P_{\text {anion }}$

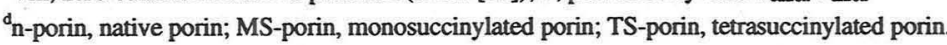


The succinylation of native R.c.-porin indicated the combination of tertiary structure-selective chemical modification and mass spectrometry as a powerful approach for the molecular structure-function evaluation of channel proteins. These results have been already extended to other ion channels, using succinylation as a specific chemical probe, such as in the crystallisation and mass spectral characterisation of the Omp32 porin from Comamonas acidovorans [52]. Moreover, a water-soluble, tetrasuccinylated form of R.c.-porin has been recently prepared; this succinyl-derivate had still native-like ion transport properties, yet characteristic, different succinylation sites at the inner channel surface were found [54]. These results suggest possible applications of chemical modification and mass spectrometry for probing the conformation-dependent gating effects of ion channels [55].

\subsection{STRUCTURE ELUCIDATION OF A SUCROSE-SPECIFIC PORIN FROM SALMONELLA THYPHIMURIUM}

In comparison to ion channels, the structure elucidation and characterisation of transport properties of specific porins are only in an initial state. A first x-ray crystal structure has been obtained for the sucrose-specific porin from Salmonella Thyphimurium (scry-porin; s. Figure 8) [56]. This porin has recently found much interest due to the presence of both a $\beta$-barrel-type channel structure, and an additional $\mathrm{N}$-terminal polypeptide chain containing a putative leucine-zipper motif [53] (s. Figure 9). The crystal structure of scry-porin is shown in Figure 8 which clearly delineates the $\beta$-barrel transmembrane topology, as well as periplasmic and external loops [57,58]. Surprisingly, no suitable electron density has been found for the $\mathrm{N}$-terminal polypeptide chain to derive information about its structure and topology; hence a possible periplasmic association and function of this $\mathrm{N}$-terminal partial sequence (1-63) is unknown at present (Figure 9).

The systematic analysis of porins, as well as other detergent-solubilised membrane proteins by MALDI-MS with high sensitivity has recently become amenable through the development of suitable matrix/sample preparation procedures [53]. A crucial step for optimal sample preparation has been the addition of detergent-containing protein solution to a preformed layer of matrix (such as $\alpha$-cyano-4-hydroxy-cinnamic acid [6]) by treatment with micro-ultrasonication which results in homogeneous microcrystalline samples [52,53]. The importance of using suitable detergent types and concentrations is illustrated in Figure 10 by MALDI spectra of native scry-porin, isolated from $S$. Thyphimurium. The spectrum obtained from a sample solubilised in n-octylglucoside ( $\mathrm{n}-\mathrm{OG}$ ) above the critical micelle concentration ( $\mathrm{cmc} ; 0.26 \%$ ) yielded abundant singly and doubly charged molecular ions providing an exact molecular weight determination for the intact protein $\left((1-483) ; \mathrm{M}_{\mathrm{W}}, 53164 \mathrm{Da}\right)$. By contrast a sample rebuffered in n-dodecylmaltoside at low concentration showed considerable degradation with molecular ions $\left(\mathrm{M}_{\mathrm{D}}, 46241 \mathrm{Da}\right)$ due to removal of the $\mathrm{N}$-terminal polypeptide (1-63).

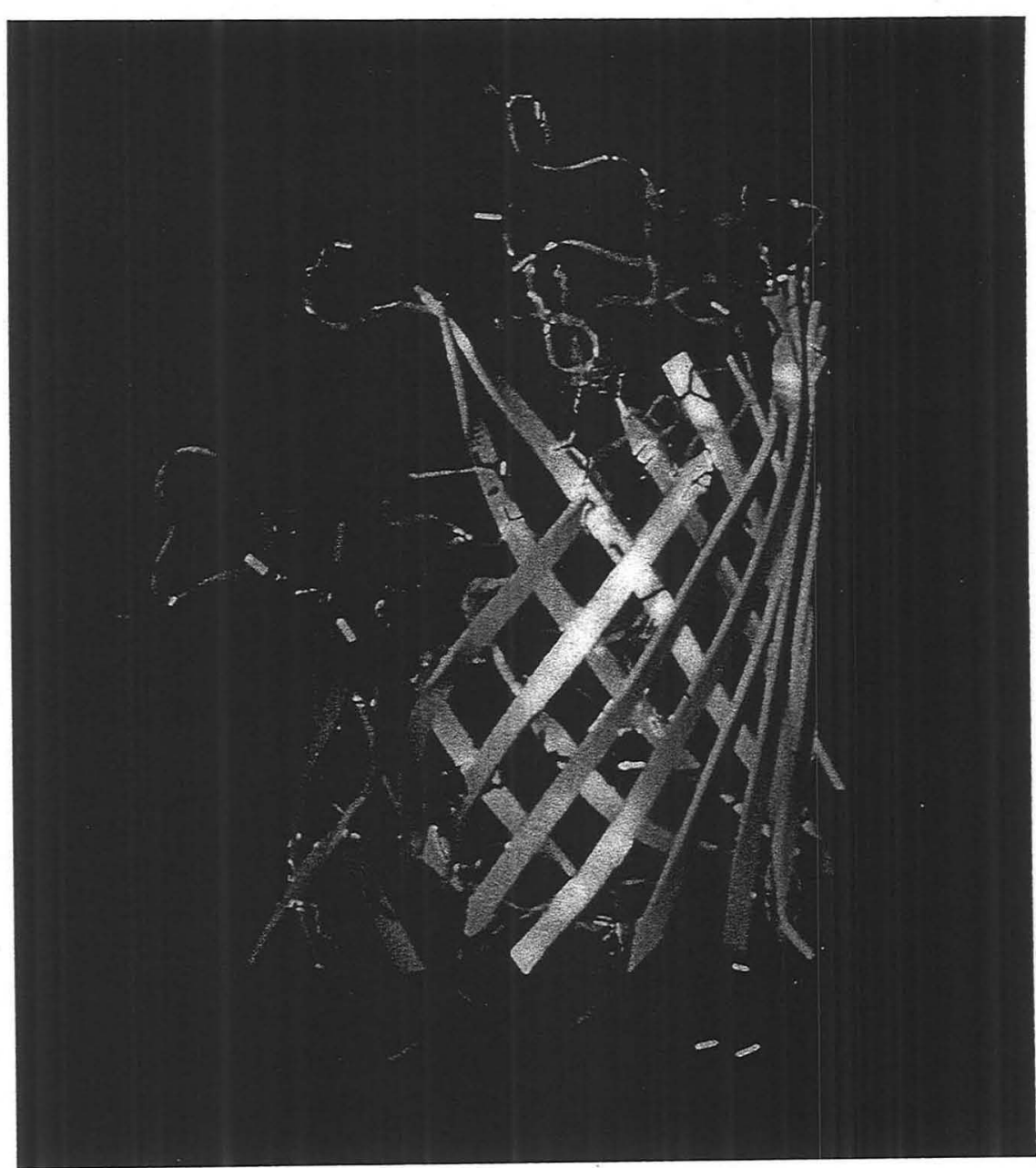

Figure 8. Structure of scry-porin from $x$-ray crystallography, showing the channel composed of $\beta$-barrel transThe formation of a truncated form of scry-porin was further ascertained by ESI-MS which yielded molecular ions with charge distributions due to the presence of a native-like and a denatured conformation (M. Przybylski et al., manuscript in preparation). This instability of scry-porin as revealed by MALDI-MS may be well explained if shielding of the protein by the detergent is insufficient to prevent its degradation by traces of proteolytic enzymes remaining from the isolation. 


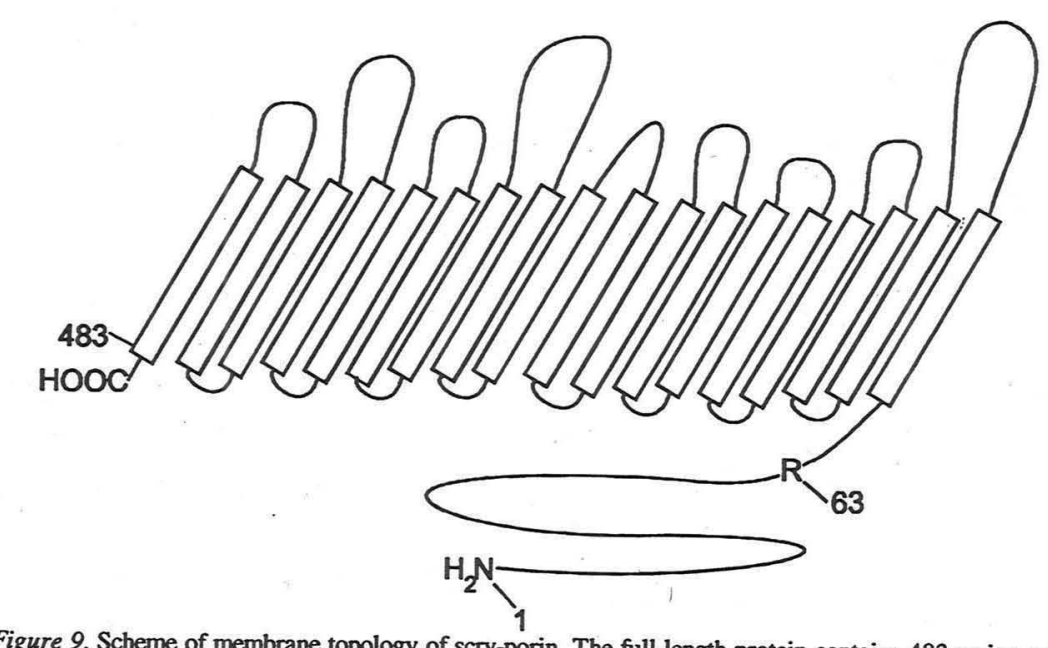

Figure 9. Scheme of membrane topology of scry-porin. The full-length protein contains 483 amino acid residues ( $\mathrm{M}_{\mathrm{w}}$ calculated: $\left.53164 \mathrm{Da}\right)$. The $\beta$-strand structure elements comprising the channel transmembrane domain are boxed. The cytoplasmic polypeptide sequence (1-63) is not detected in the crystal structure; cf. Figure 8.

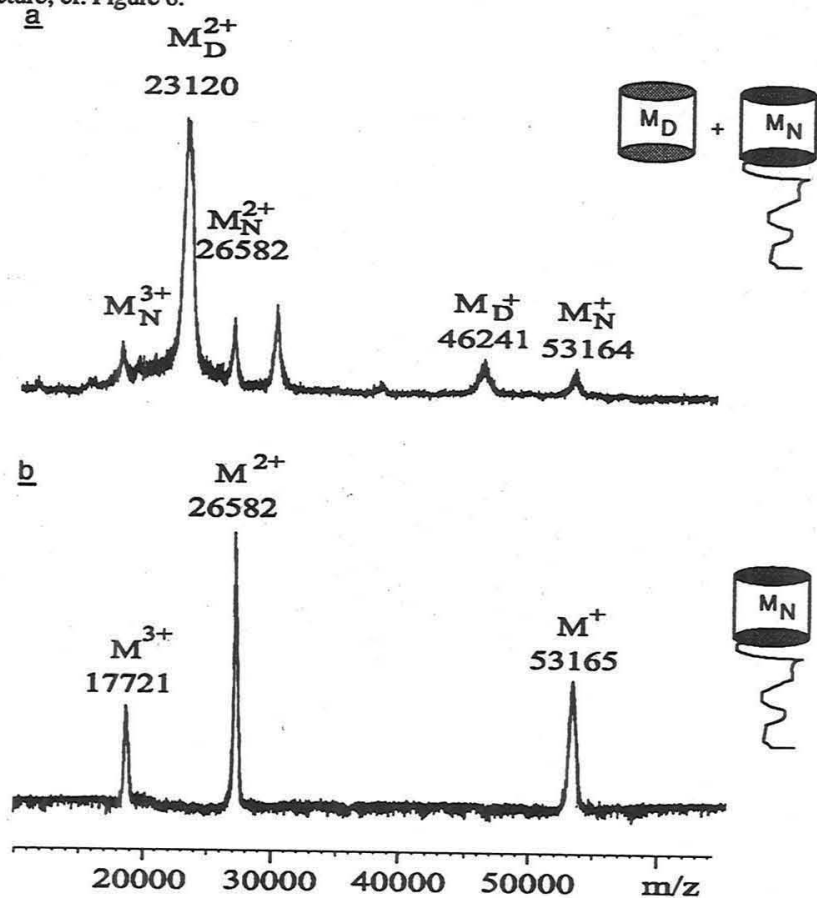

Figure 10: MALDI-mass spectrum of scry-porin ( $\left.\mathrm{M}_{\mathrm{w}}, 53164 \mathrm{Da}\right)$ prepared from a solution in $0.04 \%$ n-dodecylmaltoside (a) and $0.4 \%$ n-octylglucoside (b). Sample preparation was performed by treatment using HCCA as matrix as described in [53]; sample amount c. 10 ug. protein (1-483); $\mathrm{M}_{\mathrm{D}}$, degraded form of scry-porin lacking the $\mathrm{N}$-termin
The current results on the characterisation of scry-porin further illustrate the efficiency and complementarity of x-ray crystallography and mass spectrometry in protein structure analysis. As suggested by the topology scheme (Figure 9), recent studies indeed indicate a high susceptibility to proteolytic degradation at the conjunction of the $\beta$-barrel core to the $\mathrm{N}$-terminal polypeptide, whereas native porin channels have been found quite resistant against proteases [53,54]. For a separate structure-function analysis, the $\mathrm{N}$-terminal polypeptide (1-63) has been recently prepared by chemical synthesis.

\section{Mass Spectrometric Approaches to the Characterisation of Protein-Nucleotide} Complexes

\subsection{ELECTROSPRAY MASS SPECTROMETRY OF LEUCINE-ZIPPER POLYPEPTIDES}

Successful analyses by ESI mass spectrometry have been obtained for a variety of noncovalent complexes of biomacromolecules already as shown in recent publications, including several contributions to this volume [3,5,11-13,59]. Examples to date include a wide range of biomacromolecular complexes such as proteins with low molecular weight ligands (e.g. substrates, inhibitors), specific cofactor and metal-ion binding to proteins, antigen/epitope:antibody complexes up to homo- and heteromeric multicomponent assembly [5,60-62]. Furthermore, they encompass different binding types such as ionic interaction, co-ordinative binding and hydrogen bonds with a wide range of binding/dissociation constants. (for complexes of known structures), thus indicating the broad potential of ESI-MS. The application to "coiled-coil" types of interactions, as exemplified by the leucine-zipper polypeptides, was considered to be a particular challenge for ESI-MS due to the predominant hydrophobic binding, and their structural specificity in the interaction with poly-nucleotides $[63,64]$.

Leucine zipper classes of proteins have attracted much interest in the last years because of their functions in transcription regulation and their structure and specificity in DNA recognition $[26,27,64]$. Leucine zipper structural elements, consisting of repeating heptads of leucine residues and dominating hydrophobic and non-polar interactions, followed by a basic DNA-binding sequence have been identified in a number of transcription activator proteins, and recently in ribosomal RNA-binding proteins [64]. The hitherto best known leucine zipper is the C-terminal domain of the yeast transcription-activator GCN4, the structure of which has been characterised by $\mathrm{x}$-ray crystallography as a complex with a specific palindromic nucleotide recognition sequence [26]. As shown by the crystal structure (s. Figure 11), GCN4 assembles to a dimeric coiled-coil complex in which hydrophobic interactions between the $\alpha$-helical 
polypeptide chains are the dominant stabilizing forces. This structure thus appeared to be an appropriate model system for studying the corresponding protein-protein and protein-nucleotide interactions by ESI-MS. Initial ESI mass spectra of synthetic GCN4 peptides revealed $[65,66]$ that (i) non-covalent dimers could be identified by the specific odd-charged ions of complexes; (ii) however, their abundances relative to the monomers were weak suggesting a low stability of hydrophobic interactions under ESI conditions [5].

Synthetic polypeptides, comprising the GCN4 dimerisation and DNA-binding regions (221-281), and the suitable oligonucleotide recognition sequences are shown ion Figure 11. In a systematic study, the coiled-coil complexes of several variant peptide sequences were studied in homo- and hetero-dimerisation experiments using different equilibria ( $\mathrm{pH}$, buffer, concentration) [67], and varying desolvation potential differences between capillary tip and skimmer (repeller) electrode ( $\triangle \mathrm{CS}$ [5], in an ESI source without a countercurrent gas [68]. The identification of a leucine zipper peptide, GCN4-p1, displaying a characteristic $[\mathrm{M}+5 \mathrm{H}]^{5+}$ ion of the dimer (molecular weight,

\section{GCN $4(221-281)$}

21

$232 \quad 249 \quad 253$

$\longmapsto$ DNA binding region $\longrightarrow$

$\longmapsto$ dimerization region $\longrightarrow$

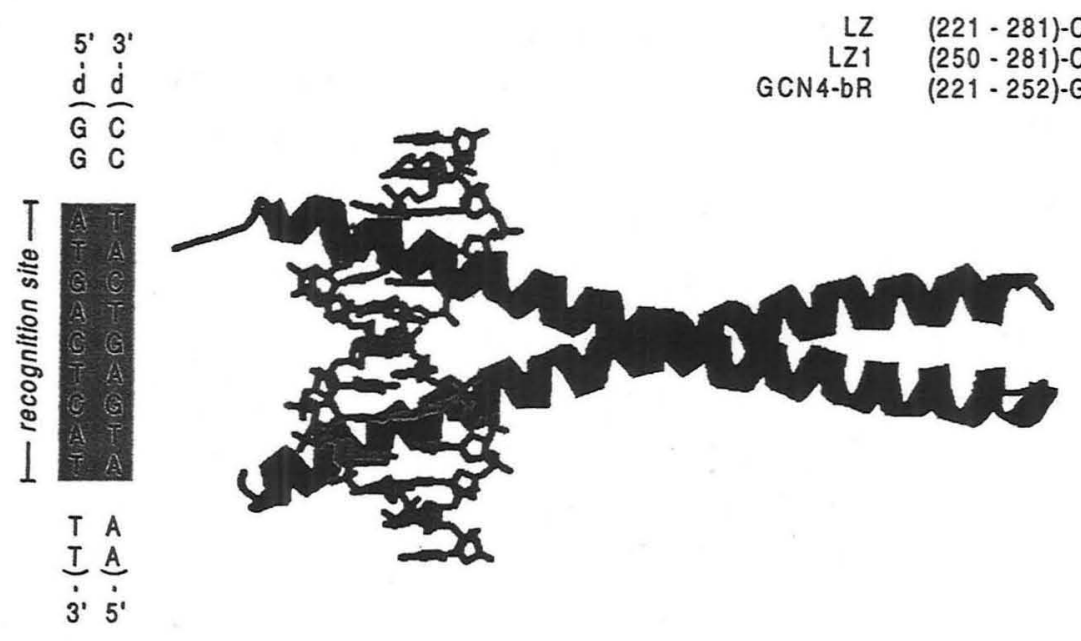

Figure 11. Structure the leucine zipper -oligonucleotide complex comprising the GCN4 polypeptide (221-281) determined by $x$-ray crystallography, and synthetic dimerisation and DNA binding peptides. site is Brookhaven National Laboratory, protein structure bank.
$8078 \mathrm{Da})$ at low desolvation potential of $10 \mathrm{~V}$, and its complete dissociation at $\Delta \mathrm{CS}=60 \mathrm{~V}$ are illustrated in Figure 12. 5+ charged ions of complexes from several synthetic leucine zipper peptides are summarised in Table 3.

These ESI spectra enabled the identification of homo- as well as hetero-dimers under mild conditions, although no quantitative formation of the weak coiled-coil complexes was obtained (presumably by adsorption processes and other dissociative conditions [67,69]). Moreover, an important result of this study was the direct identification of trimeric complexes in addition to dimers at appropriate solution equilibrium conditions and with peptide sequences that were previously shown to favour the formation of triple-stranded coiled-coil complexes [63,69].

The successful identification of intact double-stranded oligonucleotides, as well as higher-order nucleotide complexes by negative-ion ESI-MS has been shown in several recent publications $[60,70]$. as a further pre-condition for the direct analysis of protein-DNA interactions. In most cases, remarkable stabilities of multiply charged duplex ions were observed, despite some limitations imposed by purification problems of polynucleotides from contaminating alkali salts [67] and by limitations of the molecular weight (mass/charge) range attainable [5]. First model studies of polypeptide complexes with small nucleotides such as ATP/GTP successfully revealed intact molecular ions using a conventional quadrupole mass analyser with limited $\mathrm{m} / \mathrm{z}$ range $[44,67]$. However, they failed to provide ions of higher charge state for leucine zippernucleotide complexes. It should be pointed out that the effects on charge structures of proteins upon polar interaction with an oligonucleotide backbone are still unknown, as

Ac-RMKQLEDK VEELLLSK NYHLENE VARLKKL VGER-CONH 2

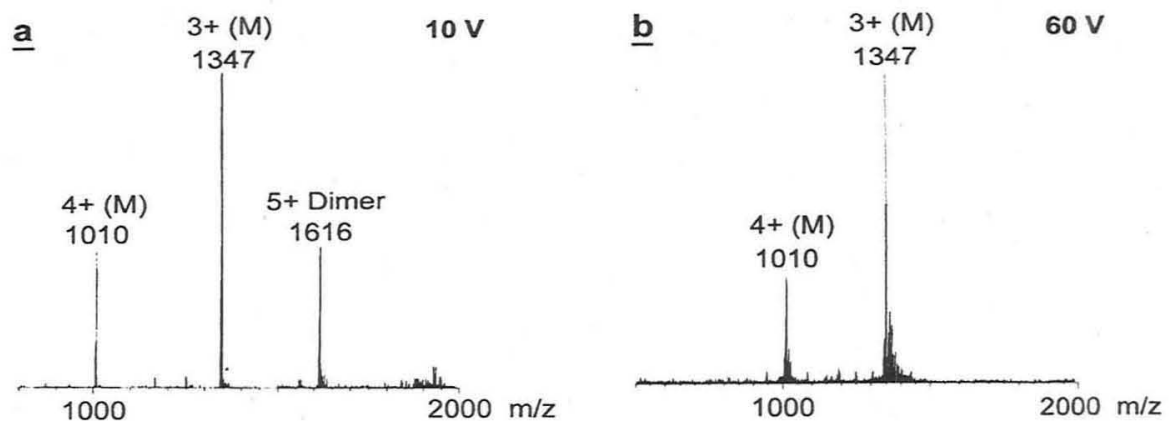

Figure 12. ESI Mass spectra of leucine zipper polypeptide GCN4-pl (249-281) at $10 \mathrm{~V}$ (a) and $60 \mathrm{~V}$ (b) declustering voltage. The $[\mathrm{M}+5 \mathrm{H}]^{5+}$ ion of the dimer is only observed at $\Delta \mathrm{CS}=10 \mathrm{~V}$. Spectra were obtained by injection of $5 \mu \mathrm{l}$ of a $50 \mathrm{mM}$ peptide solution in amixture of $2 \mathrm{mM}$ ammoniumacetate : methanol. 9:1 at oH 6.0 I671. 
are the multiply charged ions detectable by ESI-MS. Recently, the use of ESI-time-offlight instruments have clearly shown advantages for detecting high-mass complex ions [71], as illustrated by the ESI spectra of the intact complex of the GCN4 (221-281) leucine zipper with its recognition duplex-oligonucleotide. The molecular weight of the synthetic complex was determined with high accuracy despite its relatively low purity (Figure 13). These results give promise to the further evaluation of basic leucine zipper-DNA complexes by ESI-(TOF)-MS.

TABLE 3. ESI-Mass spectrometric identification of dimer and trimer coiled-coil complexes of synthetic peptides comprising dimerisation regions of leucine zippers (cf. Figure 11).

\begin{tabular}{ccccc} 
& & $\mathrm{mw}(\mathrm{Da})$ & charge & strands \\
\hline GCN4-p1 & $\mathrm{Ac}-(249-281)-\mathrm{CONH}_{2} / 4039$ & 8079 & $5+$ & dimer \\
LZ1 & $\mathrm{H}-(250-281)-\mathrm{CONH}_{2} / 3956$ & 7941 & $5+$ & dimer \\
$\mathrm{GCN}^{2} 35$ & $\mathrm{H}-(246-281)-\mathrm{CONH}_{2} / 4456$ & 8911 & $5+$ & dimer \\
LZ $^{\mathrm{c}}$ & $\mathrm{Ac}-(1-29)-\mathrm{CONH}_{2} / 3308$ & 9925 & $5+$ & trimer \\
& & & & dimer \\
LZ12A $^{\mathrm{c}}$ & $\mathrm{Ac}-(1-29)-\mathrm{CONH}_{2}-\mathrm{A} 12 \mathrm{~L} / 3266$ & 9697 & $5+$ & trimer \\
& & & & dimer \\
\hline
\end{tabular}

${ }^{2}$ Sequence numbering of GCN4 peptides refers to numbers in Figure 11. All peptides were prepared by solid-

phase synthesis procedures as described in [67].
b Molecular weights were derived from the most abundant charge states of complex ions.

c "Coil-Ser"leucine-zipper [63]; LZ, Ac-EYEALEKKLAALEAKLQALEKKLEALEHG-NH ${ }_{2 ;}$ LZ12A, exchange

of $\mathrm{L} / \mathrm{A}$ at position 12

\subsection{CHARACTERISATION OF LEUCINE ZIPPER-NUCLEOTIDE INTERAC- TIONS BY CHEMICAL MODIFICATION AND MASS SPECTROMETRY}

The successful application of specific chemical modifications at basic residues in proteins [16,17] should render this method to be a promising tool for the molecular characterisation of interaction regions in leucine zipper proteins. In a recent model study, synthetic sequences of GCN4 encompassing the DNA recognition region were subjected to chemical modification reactions of Lys and Arg residues, aimed at modifiying the structure and charges interacting with the corresponding duplex nucleotide. An illustrative example is the modification of the peptide GCN4bR (221252) which was converted into a covalent dimer by introducing an intermolecular cystinyl-disulfide, by lysine-succinylation [67]. The mass spectrometric analysis revealed specific succinylation at three Lys residues (Lys-232, -247, -252) and the $\mathrm{N}$-terminus of each peptide chain (Figure 14). DNA binding studies with this peptide showed a dramatic effect of the charge reversal due to the succinylation, despite the
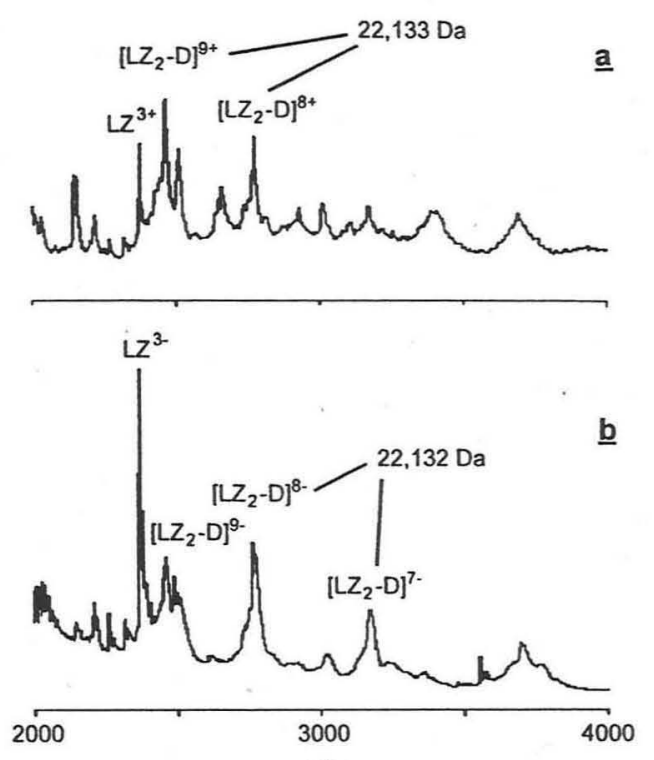

Figure 13. Positive ion (a) and negative ion (b) ESI-TOF mass spectrum of a GCN4 (221-281)-leucine zipper complex (molecular weigh, 22,131 Da). The synthetic oligonucleotide duplex used is shown in Fig. 11. Sample preparation conditions were as described in refs. [67,69] (spectra obtained at the University of Manitoba; courtesy of I. Chernushevitch).
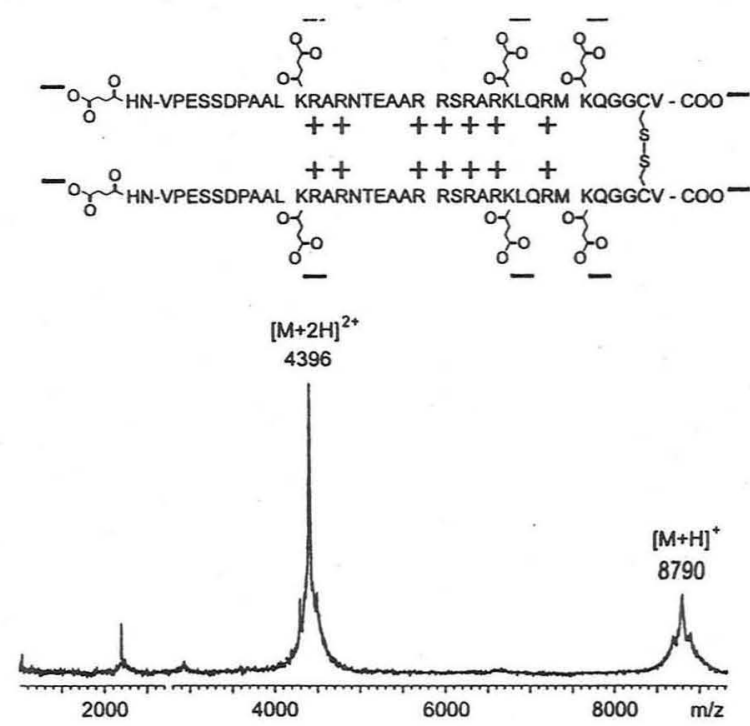

Figure 14. MALDI mass spectrum of the synthetic, succinylated polypeptide GCN4bR, intermolecular disulfide, encompassing the GCN4 basic DNA binding region (221-252) (s.Fig. 11). The peptide was disuccine, encompassing the GCN4 basic DNA binding region (221-252) (s.Fig. 11). The peptide 


\section{succinylated GCN4-bR + substrate DNA (24 bp)}

a

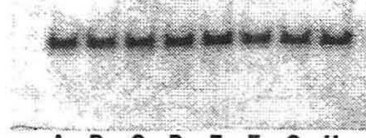

A B C DEF G H

GCN4-bR + substrate DNA (24 bp)

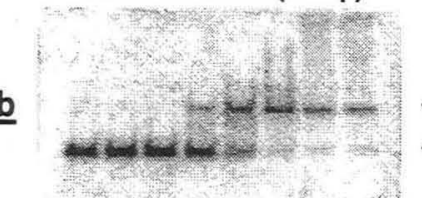

A B C D E F G H succinylated GCN4-bR + non-substrate DNA (24 bp)

duplex DNA

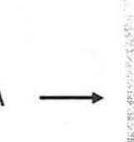

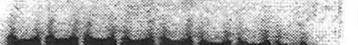

$A B C D E F G H$

GCN4-bR + non-substrate DNA (24 bp) peptide-DNA complex $\rightarrow$ - peptide-DNA complex $\rightarrow$ duplex DNA

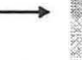

A B C DEF G H

Figure 15. Polyacrylamide gel elctrophoresis band shift analysis upon binding of unmodified and octasuccinylated GCN4bR peptide to substrate and non-substrate oligonucleotide. The substrate $24 \mathrm{bp}$ nucleotide contained the $9 \mathrm{bp}$ palindromic GCN4 recognition site shown in Figure 11. The non-substrate synthetic nucleotide was 5'-ATCATCATCATCAGTAGTAGTAGT-3'. Binding studies were performed with equimolar mixtures of complementary oligonucleotides which were annealed for $30 \mathrm{~min}$ at $80^{\circ} \mathrm{C}$ in $0.1 \mathrm{M}$ ammonium acetate. Different amounts of unmodified or succinylated peptides were then added, respectively, and each solution was incubated for $30 \mathrm{~min}$ at $25^{\circ} \mathrm{C}$

presence of multiple cationic sites at Arg residues. Using a suitable substrate 24-bp oligonucleotide (with the palindromic GCN4-specific site) and a non-substrate DNA (24-bp duplex without GCN4 recognition site), the unmodified GCN4-bR provided the specific peptide-nucleotide complex, and also bound non-substrate DNA to several unspecific duplex/peptide adducts. In the succinylated peptide, binding to the recognition-nucleotide was completely abolished as revealed by gel electrophoresis band shift analysis, and no binding was observed with non-substrate DNA (Figure 15). Corresponding modifications in synthetic partial sequences hence appear feasible to the detailed evaluation of the structural specificity and sites of DNA interaction. Such studies with peptide mixtures by ESI-MS are performed at present in our laboratory.

\section{Conclusions and Perspectives}

The analytical development of "soft"-ionisation methods of mass spectrometry (in particular, ESI-MS and MALDI-MS), and recent results by several laboratories both give promise to the perspective of protein-chemical modification in combination with mass spectrometry, as a powerful tool for characterising higher-order protein structures

and supramolecular association [3,5]. A considerable part of these new possibilities has come from the development of ESI-MS for the analysis of proteins and, particularly, the feasibility to specific non-covalent complexes $[5,7,72,73]$; in the latter area, ESI-MS provides a new powerful dimension and complements classical techniques of lower specificity for probing biomacromolecular interaction such as gel electrophoresis and sedimentation equilibrium analysis [74-79]. It will be interesting to evaluate to which extent the initial attempts for probing non-covalent interactions by MALDI-MS from the solid state $[80,81]$ can be developed to comparable selectivity by ESI-MS. Furthermore, the feasibility of both ESI-MS and MALDI-MS for the exact characterisation of chemically modified proteins, even with partial modifications and multicomponent mixtures, is a first key step in applications to structure-function studies. This feature not only provides the precise determination of modification degrees and sites (using suitable degradation and peptide mapping methods), and thereby the basis for the development of high chemical selectivity in amino acid modifying reactions $[3,82]$. The comparative analysis of multiple charge structures of ions by ESI-MS also provides a suggestion as to the presence of a still functional "native-like" protein derivative [5,11]. Hence, mass spectrometry appears to constitute the analytical basis for applications to two most important topics of structural biology which hitherto have not been fully amenable to protein chemistry, molecular recognition structures and biomacromolecular interaction.

\section{Acknowledgements}

We gratefully acknowledge the enthusiasm, ideas and contributions by several coworkers of our laboratories at the Faculty of Chemistry and Biology, particularly Christoph Borchers, Martin Blüggel, Winfried Fiedler, Martina Jetschke, Marcus Macht, and Petra Mayer. Furthermore, we wish to thank many colleagues for their helpful suggestions and advice, amongst them K.P. Schäfer, B. Penke, U. Krawinkel, G. Jung, K. Tomer, M. Sprinzl, and P. Roepstorff. We also thank I. Chernushevitch and K. Standing for their help with ESI-time-of-flight spectra. This work has been supported by the Deutsche Forschungsgemeinschaft; Bundesministerium für Wissenschaft und Forschung, Bonn, FRG; The European Union (Network: "Peptide and Protein Structure Elucidation by Mass Spectrometry"), and the BadenWürttemberg - Hungarian Science Collaboration Programme.

\section{References}

1. Burlingame, A.L. and Carr, S.A. (1996) Mass Spectrometry in the Biological Sciences. Humana Press, Totowa (N.J.). 
2. Hillenkamp, F., Karas, M., Beavis, R.C., and Chait, B.T. (1991) Matrix-assisted laser desorption/ionisation mass spectrometry of biopolymers, Anal. Chem. 63, 1193A-1203A.

3. Przybylski, M. (1995) Mass spectrometric approaches to the characterization of tertiary and supramolecular structures of biomacromolecules, Adv. Mass Spectrom., 13, 257-283.

4. Loo, J.A., Edmonds, C.G., Smith, R:D., Lacey, M.P., and Keough, T. (1990) Comparison of electrospray ionisation and plasma desorption mass spectra of peptides and proteins, Biomed Env. Mass Spectrom. 19, 286-294.

5. Przybylski, M. and Glocker, M.O. (1996) Electrospray mass spectrometry of biomacromolecules complexe with non-covalent interactions - new analytical perspectives for supramolecular chemistry and molecular recognition processes, Angew. Chem. Int. Ed. Engl., 35, 806-826.

6. Overberg, A., Hassenbürger, A., and Hillenkamp, F. (1994) Laser desorption mass spectrometry. Part II: Performance and applications of matrix-assisted laser desorption/ionization of large biomolecules, in Mass Spectrometry in the Biological Sciences: A Tutorial, M. Gross, Ed., Kluwer Academic Publishers, Dordrecht, pp. 181-197.

7. Smith, R.D., Loo, J.A., Ogorzalek-Loo, R.R., Busman, M., and Udseth, H.R. (1991) Principles and practice of electrospray ionization-mass spectrometry in peptide and protein chemistry, Mass Spectrom. Rev., 10, 359452.

8. Roepsdorff, P., Nielsen, P.F., Klarskov, K., and Højrup, P. (1988) Application of plasma desorption mass spectrometry in peptide and protein chemistry, Biomed. Env. Mass Spectrom., 16, 9-18.

9. Svoboda, M., Przybylski, M., Schreurs, J., Mijajima, A., Hogeland, K., and Deinzer, M. (1991) Mass spectrometric determination of glycosylation sites and oligosaccharide composition of insect-expressed mouse intereulin $J$. Chromatogr, 562, 403-411.

10. Glocker, M., Arbogast, B., Milley, B., Cowgill, C., and Deinzer, M.L. (1994) Disulfide linkages in the in vitro refolded intermediates of recombinant human macrophage-colony-stimulating factor: Analysis of the sulfhydryl alkylation of free cysteine residues by fast atom bombardment mass spectrometry (FABMS), Proc. Natl. Acad. Sci. USA, 91, 5868-5872.

11. Smith, R.D. and Light-Wahl, K.J. (1993) The observation of non-covalent interactions in solution by electrospray ionization mass spectrometry: promise, pitfalls and prognosis, Biol. Mass Spectrom., 22, 493 501.

12. Aplin, R.T. (1997) Probing molecular association by ESI-MS: From enzyme active site mimics to proteinprotein interactions; presented at this meeting.

13. Van Dorsselaer, A. (1997) Use of ESI-MS for characterisation of supramolecular edifices: formation of intermediates and determination of stability constants; presented at this meeting.

14. Nielsen, P.F., Schneider, K., Suckau, D., Landis, B., and Przybylski, M. (1990) Applications of selective chemical reactions in combination with 252-californium plasma desorption mass spectrometry in protein structure analysis, E. Hilf, (ed.), Mass Spectrometry of Large Non-Volatile Molecules 3, World Scientif. London, pp. 194-207.

15. Krell, T., Horsburgh, M.J., Cooper, A., Kelly, S.M., and Coggins, J.R. (1996) Localization of the active site of type II dehydroquinases, J. Biol Chem., 271, 24492-24497.

16. Glocker, M.O., Borchers, C., Fiedler, W., Suckau, D., and Przybylski, M. (1994) Molecular characterizatio of surface topology in protein tertiary structures by amino-acylation and mass spectrometric peptide mapping, Bioconj. Chem., 5, 583-590.

17. Suckau, D., Mák, M., and Przybylski, M. (1992) Protein surface topology probing by selective chemical modification and mass spectrometric peptide mapping, Proc. Natl. Acad. Sci. USA, 89, 5630-5634.

18. Suckau, D., Köhl, J., Karwath, G., Schneider, K., Bitter-Suermann, D., and Przybylski, M. (1990) Molecular epitope identification by limited proteolysis of an immobilized antigen-antibody complex and mass spectrometric peptide mapping, Proc. Natl. Acad. Sci. USA, 87, 9848-9852.

19. Steiner, R.F., Albaugh, S., Fenselau, C., Murphy, C., and Vestling, M. (1991) A mass spectrometry method for mapping the interface topography of interacting proteins, illustrated by the melittin-calmodulin system, Anal. Biochem., 196, 120-125.

20. Fiedler, W., Macht, M., Glocker, M.O., Kaufmann, I.G., Kürzinger, K., and Przybylski, M. (1995) Mass spectrometric characterization of epitope structures in protein antigens -affinity mass spectrometry, Protein Sci., 4, 122.
21. Macht, M., Fiedler, W., Kürzinger, K., and Przybylski, M. (1996) Mass spectrometric mapping of protein epitope structures of myocardial infarct markers myoglobin and troponin T, Biochemistry, 35, 15633-15639.

22. Kalkum, M., Glocker, M.O., Jetschke, M.R., Borchers, C., Przybylski, M., Saletti, R., and Foti, S. (1995) Modification of histidine and arginine residues in peptides and proteins with amino acid selective reagents and mass spectrometric characterization of the reaction products, Eur. J. Clin. Chem. Clin. Biochem., 33, A26A27.

23. Kussmann, M. and Przybylski, M. (1995) Tertiary structure-selective characterization of protein dithiol groups by phenylarsinoxide modification and mass spectrometric peptide mapping, L. Packer, (ed.), Methods in Enzymology , Academic Press, pp. 430-435.

24. Papac, D. I. Hoyes, J., and Tomer, K.B. (1994) Epitope mapping of the gastrin-releasing peptide/antibombesin monoclonal antibody complex by proteolysis followed by matrix-assisted laser desorption ionisation mass spectrometry, Prot. Sci., 3, 1485-1492.

25. Welte, W., Nestel, U., Wacker, T., and Diederichs, K. (1995) Structure and function of the porin channel, Kidney Int., 48, 930-940.

26. Ellenberger, TE., Brandl, C.J., Struhl, K., and Harrison, S.C. (1992) The GCN4 basic region leucine zipper binds DNA as a dimer of uninterrupted alpha helices: crystal structure of the protein-DNA complex. Cell, 71, 1223.

27. O'Shea, E.K., Klemm, J.D., Kim, P.S., and Alber, T. (1991) X-ray structure of the GCN4 leucine zipper, a two-stranded, parallel coiled coil, Science, 254, 539-544.

28. Glazer, A.N. (1976) The chemical modification of proteins by group-specific and site-specific reagents, H. Neurath and R.L. Hill, (eds.), The Proteins, 2, Academic Press, New York, pp. 1-103.

29. Kaplan, H., Stevenson, K.J., and Hartleys, B.S. (1971) Competitive Labelling, a method for determining the reactivity of individual groups in proteins. Biochem. J., 124, 289-299.

30. Burnens, A., Binz, H. Bosshard, H.R., Corradin, G. and Demotz, S. (1987) Epitope mapping by chemica modification of free and antibody-bound antigen. Science, 235, 780-783

31. Berzofsky, J.A. (1985) Intrinsic and extrinsic factors in protein antigenic structure, Science, 229, $932-940$

32. Wüthrich, K (1989) The development of nuclear magnetic resonance spectroscopy as a technique for protein structure determination, Acc. Chem. Res., 22, 36-44.

33. McPherson, A. (1990) Current approaches to macromolecular crystallization, Eur. J. Biochem., 189, 1-23.

34. Miranker, A., Radford, S.E., Karplus, M., and Dobson, C.M. (1991) Demonstration by NMR of folding domains in lysozyme, Nature, 349, 633-636.

35. Smith, L.J., Sutcliffe, M.J., Redfield, C., and Dobson, C.M. (1991) Analysis of Phi and Chi-1 torsion angle for hen lysozyme in solution from H-1-NMR spin spin coupling-constants, Biochemistry, 30, 986-996.

36. Drenth, J. (1994) Principles of protein $x$-ray crystallography. Springer,New York.

37. Przybylski, M., Borchers, C., Sukau, D., Mak, M., and Jetschke, M. (1993) Selective chemical modification and mass spectrometric peptide mapping- a new approach for the molecular characterisation of surface topoln "Peptides 1992" (C. H. Schneider, A.N. Eberle, eds.), Escom Sci. Publ., Amsterdam, 83-85).

38. Rayment, I., Rypniewski, W.R., Schmidt-Base, K., Smith. R., Tomchick, D.R., Benning, M.M., Winkelmann D.A., Wesenberg, G. and Holden, H.M. (1993) Three-dimensional structure of myosin subfragment-1: a molecular motor, Science, 261, 50-58.

39. Happersberger, P., Cowgill, C., Deinzer, M.L., and Glocker, M.O. (1996) Characterization of protein-folding intermediates by chemical trapping and mass spectrometry, 44th ASMS Conference on Mass Spectrometry and Allied Topics, 1050

40. Patthy, L. and Smith, E.L. (1975) Reversible modification of arginine residues. Application to sequence studies by restriction of tryptic hydrolysis to lysine residues. J. Biol. Chem., 250, 557.

41. Lee, B. and Richards, F.M. (1971) The interpretation of protein structures: estimation of static accessibilities. J. Mol. Bio., 55, 379-400.

42. Spassov, VZ., Karshikov, A.D., and Atamasov, B.P. (1989) Electrostatic interactions in proteins. A theoretical analysis of lysozyme ionization, Biochim. Biophys. Acta, 999, 1-6. 
43. Welte, W., Przybylski, M., Glocker, M.O., Diederichs, K., Benz, R., and Breed, J. (1997) X-ray crystallographic and mass spectrometric structure determination and functional characerisation of succinylated porin from Rhodobacter capsulatus: Implications for ion selectivity and single-channel conductance, pp. 239-276.

44. Glocker, M.O., Nock, S., Sprinzl, M., and Przybylski, M. (1997) Characterisation of surface topology and binding surfaces in complexes of the elongation factor proteins EF-Ts and EF-Tu from Thermus thermophilus by chemical modification and mass spectrometry, Chemistry, in press.

45. Fiedler,W., Borchers, C., Kürzinger, K., Macht, M., Deininger, S., and Przybylski, M. (1997) Molecular characterisation of conformational epitopes of hen eggwhite lysozyme by differential chemical modification of immune complexes and mass spectrometric peptide mapping, Bioconj. Chem., submitted for publication.

46. Borchers, C. (1996), PhD dissertation, University of Konstanz.

47. Wattenberg A. (1996), Dipl.-Thesis, University of Konstanz.

48. Brünger, A.T. (1993) Assessment of phase accuracy by cross validation: the free R-value. Methods and applications, Acta Crystallogr., D49, 24-36.

49. Nestel, U., Wacker, T., Woitzik, D., Weckesser, D., Kreutz, W., and Welte, W. (1989) Crystallisation and preliminary X-ray analysis of proin from Rhodobacter capsulatus, FEBS Lett., 242, 405.

50. Benz, R. (1988) Structure and function of porins from gram-negative bacteria, Annv. Rev. Microbiol., 42, 359-393.

51. Przybylski, M., Glocker, Nestel, U., Schnaible, V., Blüggel, M., Diederichs, K., Weckesser, J., Schad, M. Schmid, A., Welte, W., and Benz, R. (1996) X-ray crystallographic and mass spectrometric structure determination and functional characterisation of succinylated porin from Rhodobacter capsulatus: Ietermination and functional characterisation of succinylated porin from Rhodobacter capsulations for ion selectivity and single-channel conductance, Protein Sci., 5, 1477-1489.

52. Zeth, K., Schnaible, V., Przybylski, M., Welte, W., Diedrichs, K., and Engelhardt, H. (1997) Crystallisation and mass spectrometric analysis of native and chemically modified porin Omp 32 from Comamonas acidovorans, FEBS-Lett., in press.

53. Schnaible, V.,Michels, J., Zeth, K., Freigang, J., Welte, W., Bühler, S., Glocker, M.O., and Przybylski, M. (1997) Approaches to the characterisation of membrane channel proteins (porins) by UV-MALDI mass spectrometry, Int. J. Mass Spectrom. Ion Proc, in press.

54. Bühler, S., Schnaible, V., Glocker, M.O. Michels, J., Zeth, K., Welte, W., and Przybylski, M. (1997) Conformational differentiation of two porin forms by selective chemical modification and MALDI-MS, 14th International Mass Spectrometry Conference.

55. Jordon, P. (1987) How pore mouth charge distributions alter the permeability of transmembrane ionic channels, Biophys. J., 51, 297-311.

56. Forst, D., Schülein, K., Wacker, T., Diederichs, K., Kreutz, W., Benz, R., and Welte, W. (1993) Crystallisation and preliminary $\mathrm{X}$-ray diffraction analysis of Scry, a specific bacterial outer membrane porin. J. Mol. Biol., 229, 228-262.

57. Schülein, K., Anderson, C., and R., B. (1995) The deletion of 70 amino acids near the N-terminal end of the sucrose-specific porin Scry causes its functional similarity to LamB in vivo and in vitro., Mol. Microbiol. $17,757-767$

58. Forst, D. (1996), PhD dissertation, University of Konstanz.

59. Henion, J., Li, Y.T., Hsieh, Y.L., and Ganem, B. (1993) Mass spectrometric investigations of drug-receptor interactions, Therap. Drug Monitor., 15, 563.

60. Light-Wahl, K.J., Springer, D.L.,Winger, B.E., Edmonds, C.G., Camp, D.G., Thrall, B.D., and Smith, R.D. (1993) Observation of a small oligonucleotide duplex by electrospray ionisation mass spectrometry, J. Am. Chem. Soc. 226, 803-804.

61. Baca, M. and Kent S.B.H. (1992) Direct observation of a ternary complex between the dimeric enzyme HIV1 protease and a substrate-based inhibitor, J. Am. Chem. Soc., 114, 3992-3993.

62. Leize, E., van Dorsselar, A., Krämer, R. and Lehn, J.M. (1993) Electrospray mass spectrometry of the self assembly of a capped polymetallic complex, J. Chem. Soc. Chem. Commun., 990-993.

63. Lovejoy, B., Choe, S., D, C., McRorie, D.K., DeGrado, W.F., and Eisenberg, D. (1993) Crystal structure of a synthetic $\alpha$-helical bundle, Science, 259, 1288-1293.

64. Hurst, R.S. (1994) Transcription factors 1:bzip proteins, P. Sheterline, (ed.), Protein Profile, London, pp. 123-168.
65. Li, Y.-T., Hsieh, Y.-L., Henion, J.D., Senko, M.W., McLafferty, F.W., M., and Ganem, B. (1993) Mass spectrometric studies on noncovalent dimers of leucine zipper peptides, J. Am. Chem. Soc., 115, 8409-8413. 66. Przybylski, M., Glocker, M.O., Maier, C., Borchers, C., Dürr, E., Fiedler, W., Kast, J., Wendt, H., and Bosshard, H.R. (1995) Direct characterization of supramolecular complexes of polypeptides and proteins by electrospray mass spectrometry, H. Maia, (ed.), Peptides 1994 , Escom, Leiden, pp. 43.

67. Przybylski, M., Kast, J., Glocker, M.O., Dür, E., Bosshard, H.R., Nock, S., and Sprinzl, M. (1995) Mass spectrometric approaches to molecular characterization of protein-nucleic acid interactions, Toxicology Letters, 82/83, 567-575.

68. Allen, M.H. and Vestal, M.L. (1992) Design and performance of a novel electrospray interface, J. Am. Soc Mass Spectrom., 3, 18-26.

69. Wendt, H., Dürr, E., Thomas, R.M., Przybylski, M., and Bosshard, H.R. (1995) Characterization of leucin zipper complexes by electrospray ionization mass spectrometry, Protein Sci., 4, 1563-1570.

70. Goodlett, D.R., Hardin, C.C., Corregan, M., and Smith, R.D. (1993) Estimation of quadruplex DNAT $_{M}$ by electrospray-ionization-mass spectrometry, Proc. 41st Conf. Am. Soc. Mass Spectrom., 258.

71. Chernushevitch, I., Ens, W., and Standing, K.G. (1997) Measurement of noncovalent biomacromolecula complexes with high $\mathrm{m} / \mathrm{z}$ by ESI-time-of-flight mass spectrometry, this volume.

72. Kebarle, P. and Tang, L. (1993) From ions in solution to ions in the gas phase, Anal. Chem., 65, 972A-985A.

73. Miranker, A., Robinson, C.V., Radford, S.E., Aplin, R.T. and Dobson, C.M. (1993) Detection of transient proteins folding populations by mass spectrometry, Science, 262, 896-900.

74. Phisicky, E.M. and Fields, S. (1995) Protein-protein interactions: methods for detection and analysis, Microbiol. Rev., 59, 94-123.

75. Carr, D.W., and Scott, J.D. (1992) Blotting and band-shifting: techniques for studying protein-protein interactions, Trends Biochem. Sci., 17, 246-249.

76. Darawshe, S., Rivas, G., and Minton, A.P. (1993) Sedimentation equilibrium-quantitave ployacrylamide gel electrophoresis (SE-QPAGE): a new technique for the detection of associants in multicomponent solutions, Anal. Biochem., 215, 236-242.

77. Fields, S., and Sternglanz, R. (1994) The two-hybrid system: An assay for protein-protein interactions, Trends Genet., 10, 286-292.

78. Schmidt-Dorr.T., Oertel-Buchheit, P., Pernelle, C., Bracco, L., Schnarr, M., and Granger-Schnarr, M. (1991) Construction, purification and characterisation of a hybrid protein comprising the DNA binding domain of LexA repressor and the jun leucine zipper: a circular dichroism and mutagenesis study, Biochemistry, 30, 9657-9664.

79. Stevens, F.J. (1986), Analysis of protein-protein interaction by simulation of small-zone size-exclusive chromatography: application to an antibody-antigen association, Biochemistry, 25, 981-993.

80. Glocker, M.O., Bauer, S.HJ., Kast, J., Volz, J., and Przybylski, M. (1996) Characterization of specific noncovalent protein complexes by UV-MALDI-mass spectrometry, J. Mass Spectrom., 31, 1221-1227.

81. Lechi, P. and Pannell, L.K. (1995) The detection of intact double-stranded DNA by MALDI, J. Am. Soc. Mass Spectrom., 6, 972-975.

82. Imoto, T. and Tamada, H. (1989) Chemical modification. In: Protein function, a pratical approach (T.E. Creighton, ed.), Oxford University press, pp. 247-277. 